\title{
NUMERICAL STUDY OF RECTANGULAR FIN FOR COOLING OF AUTOMOBILE ENGINE
}

\section{Mr. PREM PRAKASH PANDIT}

(PG Scholar, Department of Mechanical Engineering, IPS College of Technology \& Mgmt, Gwalior, India, premprakashpandit@gmail.com)

\section{Dr. P S CHAUHAN}

(Professor, Department of Mechanical Engineering, IPS College of Technology \& Mgmt, Gwalior, India, deanaa.ips@gmail.com)

Keywords- Governing equation, Taylor's series, Rectangular fins, partial differential equation, Boundary condition.

\section{INTRODUCTION}

In engine, the combustion of fuel occur inside the cylinder then lots of heat produced in the moving (Piston, Crankshaft, Crank) and stationary (Cylinder, Cylinder head) parts of engine, if some cooling mechanism are not provided to the engine it will melt or damage the metal parts of engine. Some heavy vehicles like four wheeler use water cooling system while two wheelers engine and light aircraft use air cooling system to dissipate heat generated during power stroke of the engine. Now these days Mahindra Tractor uses air cooling system rather than water cooling system, air cooling system have some advantages like lighter weight, easy maintenance and lesser space requirement. In air cooling system, extended surfaces called rectangular fins are provided at the outer surface or periphery of engine cylinder to raise the heat transfer rate. That is why the analysis of rectangular fin is important.

\section{LITERATURE REVIEW}

Date and Khond (2013) proposed the novel drew closer toward the heat transfer 
upgrade of plate and fin heat exchanger utilizing enhanced fin configuration encouraging the vortex generation. [1] The vortex generator can be impanted in the plane fin and that too in a minimal cost with impact the first outline and setup of the normally utilized heat exchangers. The different outline alterations like plate fin, wavy fin and compounded fin examined numerically and experimentally

Magarajan, Thundil and Elango (2012) numerical studied the heat transfer from I/C Engine cooling by extended fins using CFD. [2] Heat release from an I/C engine cylinder attached with six numbers of fins having pitch of $10 \mathrm{~mm}$ and $20 \mathrm{~mm}$ have been calculated numerically using commercially available CFD tool ANSYS Fluent. I/C engine is initially at 150 and the heat release from the cylinder, analyzed at a wind velocity of $0 \mathrm{~km} / \mathrm{h}$. It is observed from the results that it takes 174.08 seconds (pitch=10mm) and 163.17 seconds (pitch $=20 \mathrm{~mm}$ ) for ethylene glycol domain to reach to a temperature of $423 \mathrm{~K}$ to $393 \mathrm{~K}$ initially.

Matkar, Ravanan (2011) used different material like copper and aluminium to find the heat transfer rate and the temperature behaviour for the same fin. [3] They have watch that heat flow rate of copper fins $(19.2 \mathrm{~W})$ is not exactly the heat flow rate of the aluminium fins $(56.99 \mathrm{~W})$. The copper gets stable at the least temperature. Furthermore, henceforth here presume that the copper is best material suitable for fins than the aluminium.

Mishra, Nawal and Thundil (2012) did transient numerical investigation ANSYS FLUENT 12.1 CFD code with wall cylinder temperature of $423 \mathrm{~K}$ at first and the heat discharge from the C. S. barrel is examined for zero wind speed. [4] The heat discharge from the barrel which is ascertained numerically is accepted with the trial results. To expand the rate of cooling, it is necessary number of fins should be mounted on the cylinder. Be that as it may, the cylinder cooling may diminish with an increased number of fins and excessively contract a fin pitch. As air does not stream well between the fins, thus the overlapping of thermal boundary layers takes place at the lower and upper fins surfaces.

Nagarani and Mayilsamy (2010) analysed the heat transfer rate and efficiency for circular and elliptical annular fins for different environmental conditions. [5] Elliptical fin efficiency is more than circular fin. If space restriction is there along one particular direction while the perpendicular direction is relatively unrestricted elliptical fins could be a good choice. Normally heat transfer co-efficient depends upon the space, time, flow conditions and fluid properties. They concluded if there are changes in environmental conditions, there are changes in heat transfer co-efficient and efficiency also.

Patil and Rathod (2012) numerically investigated effect of operating parameters on plate fin heat exchanger. [6] Plate fin heat exchanger is analyzed for offset strip fins having rectangular cross section. A steady state model for the core dimensions of a plate fin cross flow heat exchanger has been developed using MATLAB. Design variables such as surface areas, free flow areas, exchanger core size have been calculated for the given operating parameters of cross flow CHE. The effect of effectiveness of the CHE on size of the heat exchanger has also established by varying effectiveness from 0.8 to 0.9 with different operating parameters.

Paul (2012) performed Numerical Simulations to determine heat transfer 
characteristics of different fin parameters namely, number of fins, fin thickness at varying air velocities. Experiments have been conducted with a single fin mounted on the cylinder. [7] Numerical simulation of the same setup was organized using CFD (Computational Fluid Dynamics). Cylinders with fin dimension of $4 \mathrm{~mm}$ and $6 \mathrm{~mm}$ thickness were simulated for $1,3,4$ and 6 fin configurations. They conlcluded when thickness of the fin increased reduced gap between the fins, results in swirls which helped in increasing the heat transfer. They also concluded that more number of fins with less thickness can be preferred in high speed vehicles than thick fins with less numbers because more number of fins creates more randomness and turbulence and hence increases the heat transfer.

Patil and Dange (2013) conducted experiments and CFD analysis of elliptical fins for heat transfer parameters, heat transfer coefficient and tube efficiency by forced convection. They conducted different experiments for different air flow velocity with varying heat input. [8] The CFD temperature distribution for all cases verifies with that of experimental results. They found that at air flow velocity of 3.7 $\mathrm{m} / \mathrm{s}$ heat transfer rate decreases as heat input increases. Also heat transfer coefficient ' $h$ ' is higher at above atmospheric temperature and lower at below atmospheric temperature. At air flow velocity of $3.7 \mathrm{~m} / \mathrm{s}$ efficiency increases as heat input increases.

Sanders, Wilsted and Mulaahy (1942) used one original steel fins and one 1-inch spiral copper fins brazed on the barrel for did the cooling tests on two engine cylinder. [9] The copper fins enhanced the general heat transfer coefficient from the barrel to the air 115 percent. They likewise reasoned that in the range of practical fins dimensions, copper fins having the same weight as the first steel fins will give no less than 1.8 times the overall heat transfer of the first steel fins.

Sharma, Sharma (2013) shows the results of computational numerical investigation of airflow and heat transfer in a light weight vehicles motor, considering three distinctive morphology pin fins.[10] A numerical study using Ansys fluent ${ }^{\circledR}$ (Version 6.3.26) was led to find the ideal pin shape based on minimum pressure drop and amplifying the heat transfer over the Automobile motor body. The outcomes demonstrate that the drop molded pin fins show enhanced results on the premise of heat transfer and pressure drop by comparing different fins.

The present study deals with the effectiveness of rectangular fin by taken assumption temperature independent.

\section{METHODOLOGY}

The governing equation is in the form of partial differential equation, to obtain a solution it must be expressed in the form of approximate solution, a digital computer which can perform only arithmetic and logical operations can be employed to obtain a solution. Taylor series expansion will be used to convert these partial derivative terms in algebraic form.

Finite difference technique has been used to discretize the two-dimensional heat conduction equation. Following steps has been considered to solve the governing equation,

1. Two-dimensional heat conduction equation first converted to algebraic form using Taylor series expansion.

2. Explicit scheme in time has been used to discretize temporal term. 
3. Central scheme for second order derivative has been used to discretize spatial term.

4. Collocated grid element shown in fig. 1 has been used in which all the properties are Properties of the materials have been considered in pure form, represents the properties of the materials.

5. MATLAB tool has been used to solve the problem and to find out the temperature distribution during the process.

6. Height and length of the fin has been varied to see their effect on cooling rate.

7. The final step consists in solving the problem of heat transfer controlled by the convergence condition. The result of the heat transfer is shown in 2-D, as well as the cooling curve.

\section{NUMERICAL STUDY}

Governing Equation of two- dimensional Energy

$\rho C_{p} \frac{\partial T}{\partial t}+\left(u \frac{\partial T}{\partial x}+v \frac{\partial T}{\partial y}\right)=k\left(\frac{\partial^{2} T}{\partial x^{2}}+\frac{\partial^{2} T}{\partial y^{2}}\right)$

First term on the left hand side of the equation characterizes the variation of the temperature with the time which represents the unsteady heat transfer and second term is convective part which comes into play due to movement of the molecules, while term on right hand side characterizes the variation in the spatial direction which represents the diffusive part. Other two modes of heat transfer, convection and radiation has been neglected inside the fin, because present study is focusing on designing of a solid-fin and it is well known fact that inside the solid body heat transfer by conduction dominate over convection and radiation. So the above equation will reduces to a simple form by neglecting the second term on the left hand side,

$\rho C_{p} \frac{\partial T}{\partial t}=k\left(\frac{\partial^{2} T}{\partial x^{2}}+\frac{\partial^{2} T}{\partial y^{2}}\right) \ldots \ldots \ldots$

A simplified form of the above governing equation can also be written as

$\frac{\partial T}{\partial t}=\alpha\left(\frac{\partial^{2} T}{\partial x^{2}}+\frac{\partial^{2} T}{\partial y^{2}}\right)$

Where: $\alpha=k / \rho C_{p}$ is thermal diffusivity in $\mathrm{m}^{2} / \mathrm{s}, k$ is thermal conductivity in $\mathrm{W} / \mathrm{m}-\mathrm{K}, \rho$ is density in $\mathrm{Kg} / \mathrm{m}^{3}, C_{p}$ is specific heat $\mathrm{J} / \mathrm{Kg}-\mathrm{K}, \mathrm{T}$ is temperature in Kelvin $(\mathrm{K}), \mathrm{t}$ is time in seconds.

In arithmetic, a Taylor series is a representation of a function as an infinite sum of terms that are computed from the values of the function's derivatives at a single point

Taylor series in X-direction.

$T(x+\Delta x, y)=T(x, y)+\frac{\partial T(x, y)}{\partial x} \frac{\Delta x}{1 !}+$

$\frac{\partial^{2} T(x, y)}{\partial x^{2}} \frac{(\Delta x)^{2}}{2 !}+\frac{\partial^{3} T(x, y)}{\partial x^{3}} \frac{(\Delta x)^{3}}{3 !}+O(\Delta x)^{4} .$.

$T(x-\Delta x, y)=T(x, y)-\frac{\partial T(x, y)}{\partial x} \frac{\Delta x}{1 !}+$

$\frac{\partial^{2} T(x, y)}{\partial x^{2}} \frac{(\Delta x)^{2}}{2 !}-\frac{\partial^{3} T(x, y)}{\partial x^{3}} \frac{(\Delta x)^{3}}{3 !}+$

$O(\Delta x)^{4}$

Similarly Taylor series in y-direction

$T(x, y+\Delta y)=T(x, y)+\frac{\partial T(x, y)}{\partial y} \frac{\Delta y}{1 !}+$

$\frac{\partial^{2} T(x, y)}{\partial y^{2}} \frac{(\Delta y)^{2}}{2 !}+\frac{\partial^{3} T(x, y)}{\partial y^{3}} \frac{(\Delta y)^{3}}{3 !}+$

$O(\Delta y)^{4}$.

$T(x, y-\Delta y)=T(x, y)-\frac{\partial T(x, y)}{\partial y} \frac{\Delta y}{1 !}+$

$\frac{\partial^{2} T(x, y)}{\partial y^{2}} \frac{(\Delta y)^{2}}{2 !}-\frac{\partial^{3} T(x, y)}{\partial y^{3}} \frac{(\Delta y)^{3}}{3 !}+$

$O(\Delta y)^{4}$

Equation (4) and (6) are Taylor series forward expansion in $\mathrm{x}$ and $\mathrm{y}$ direction 
respectively while equation (5) and (7) are backward expansion in $\mathrm{x}$ and $\mathrm{y}$ direction respectively.

As present problem involves both first and second and order partial derivative term first we will find the spatial terms of the heat conduction equation $\frac{\partial^{2} T}{\partial x^{2}}$ and $\frac{\partial^{2} T}{\partial y^{2}}$, adding the equation (4) and (5) and after doing some arithmetic operation we will finally get,

$\frac{\partial^{2} T}{\partial x^{2}}=\frac{T(x+\Delta x, y)+T(x-\Delta x, y)-2 T(x, y)}{(\Delta x)^{2}}+$

$O(\Delta x)^{2}$

Similarly for second order partial term in ydirection

$\frac{\partial^{2} T}{\partial y^{2}}=\frac{T(x, y+\Delta x)+T(x, y-\Delta x)-2 T(x, y)}{(\Delta y)^{2}}+$

$O(\Delta y)^{2}$

Above formulation is called central differencing scheme for second order partial derivative term, here $O(\Delta x)^{2}$ and $O(\Delta y)^{2}$ represents that the formulation is accurate up to second order.

Graphical representation of the above equation is shown in fig. Element shown in figure, represents a collocated grid where $\varphi$ can be any dependent variable. Element in left hand side fig (a) is in Cartesian form while element in right hand side fig (b) is in vector form. It is a five-node grid element $\varphi$ $(i, j)$ represents the focal node while all other nodes have been represented corresponding to this.
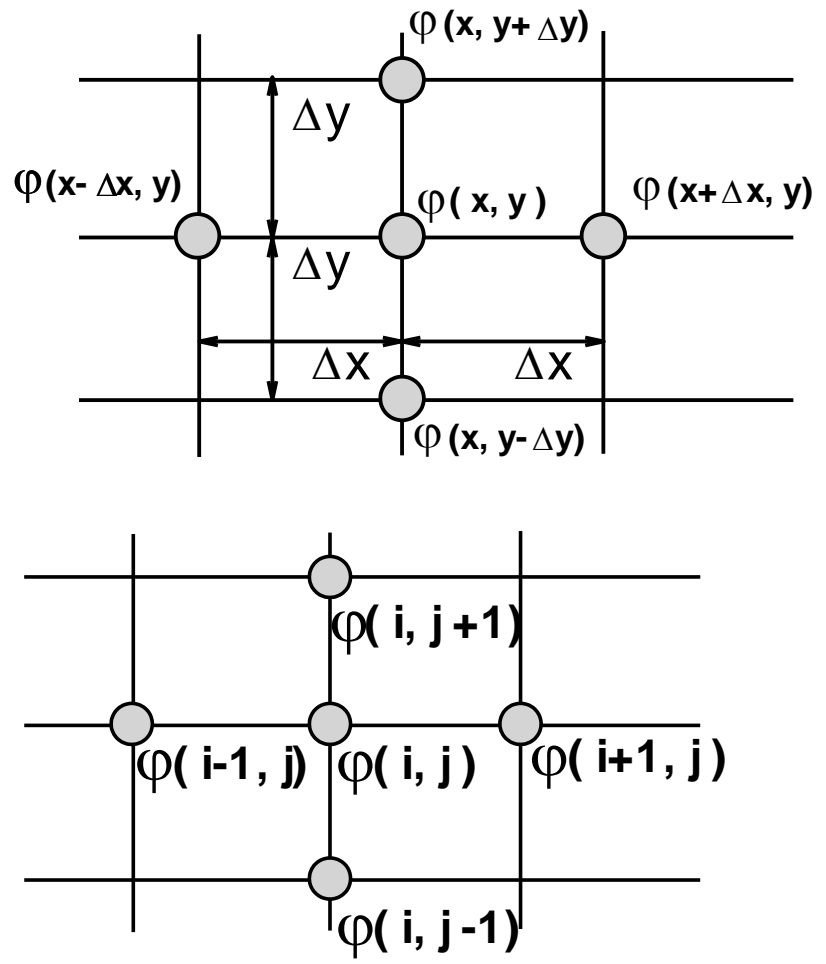

Fig.1 Grid element layout

Now the temporal derivative term is first order partial term, which can be discretized either by explicit scheme or by implicit scheme,

$\frac{T_{i, j}^{n+1}-T_{i, j}^{n}}{\Delta t}=\alpha\left(\frac{T_{i+1, j}^{n}+T_{i-1, j}^{n}-2 T_{i, j}^{n}}{(\Delta x)^{2}}+\right.$
$\left.\frac{T_{i, j+1}^{n}+T_{i, j-1}^{n}-2 T_{i, j}^{n}}{(\Delta y)^{2}}\right) \ldots \ldots \ldots \ldots \ldots \ldots \ldots \ldots$

$\frac{T_{i, j}^{n+1}-T_{i, j}^{n}}{\Delta t}=\alpha\left(\frac{T_{i+1, j}^{n+1}+T_{i-1, j}^{n+1}-2 T_{i, j}^{n+1}}{(\Delta x)^{2}}+\right.$ $\left.\frac{T_{i, j+1}^{n+1}+T_{i, j-1}^{n+1}-2 T_{i, j}^{n+1}}{(\Delta y)^{2}}\right)$

Equation (10) and (11) represents the explicit and implicit discritization of equation 3. In explicit scheme only one term is at the next time level $(n+1)$ which is an unknown quantity while all other terms are at same time level (n) which are known, while in implicit scheme spatial derivative terms are also at the next time level $(n+1)$ which makes it difficult to handle in computer code. Explicit scheme is simple to code but requires a condition to be satisfy 
which is known as stability condition and leaves a limit on the time step for a particular grid selection while implicit scheme is free of this stability condition represented in eq. (12)

$\alpha \times d t\left(\frac{1}{(d x)^{2}}+\frac{1}{(d y)^{2}}\right) \leq \frac{1}{2}$

In the present study explicit scheme has been considered for simplicity of the scheme, As we know that term at time ' $n+1$ ' is unknown while terms at time ' $n$ ' are known. So from above equation it can be observed that all the terms on right hand side are at time ' $n$ ' (known) while only one term at time ' $n+1$ ' is there in left hand side which can be easily calculated as,

$T_{i, j}^{n+1}=T_{i, j}^{n}+\alpha \Delta t\left(\frac{T_{i+1, j}^{n}+T_{i-1, j}^{n}-2 T_{i, j}^{n}}{(\Delta x)^{2}}+\right.$

$\left.\frac{T_{i, j+1}^{n}+T_{i, j-1}^{n}-2 T_{i, j}^{n}}{(\Delta y)^{2}}\right)$

\section{Boundary conditions}

Initial condition at time $\mathrm{t}=0$;

$\mathrm{T}_{\mathrm{i}}=$ Initial temperature

As we know that heat losses by fins are due to forced convection, to reach to the reality convective boundary conditions have considered on walls of the fin shown in fig 2. From the fig it can be observed that at left wall, heat flux boundary condition has been considered which represents that fin is attached to the surface of the automobile engine from left wall, which can also be seen from the arrow direction, while on other three walls convective boundary condition has been considered which represents that heat losses to the surroundings by convection, the same can be understand by arrow direction which are outward in the fin
At $x=0$

$$
q=-k \frac{\partial T}{\partial x}
$$
At $\mathrm{x}=\mathrm{L}$
$q=k \frac{\partial T}{\partial x}=$
$-h\left(T-T_{\infty}\right)$
At $\mathrm{y}=0$
$q=k \frac{\partial T}{\partial y}=$
$h\left(T-T_{\infty}\right)$
At $\mathrm{y}=\mathrm{H}$
$q=k \frac{\partial T}{\partial y}=$
$-h\left(T-T_{\infty}\right)$

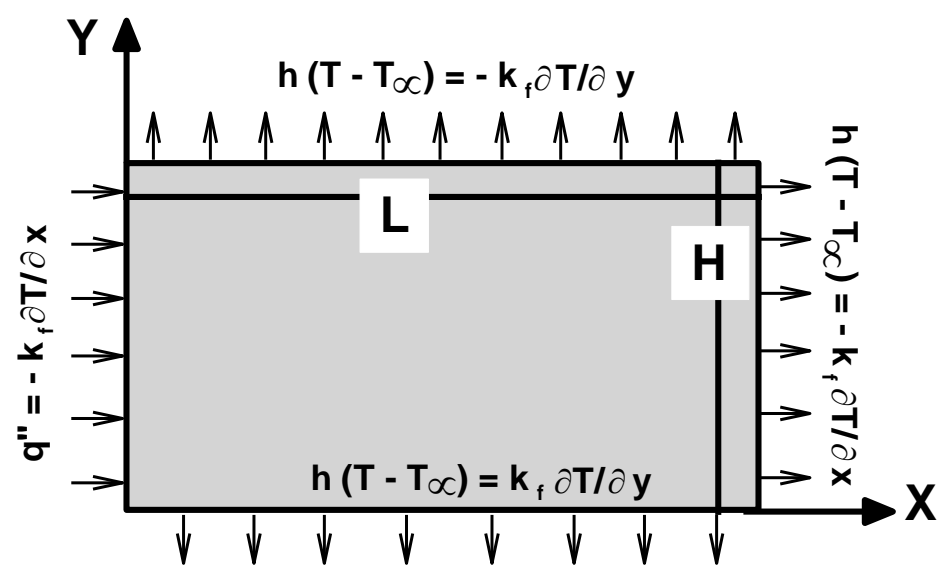

Fig.2 Schematic of fin

Where $\mathrm{q}^{\prime \prime}=$ quantity of heat transfer $\left(\mathrm{W} / \mathrm{m}^{2}\right)$

$\mathrm{h}=$ heat transfer coefficient $\left(\mathrm{W} / \mathrm{m}^{2}-\mathrm{K}\right)$

$\mathrm{T}_{\infty}=$ Ambient temperature $(\mathrm{K})$

\section{RESULT AND CONCLUSION}

In present study, Governing equation has been solved and converted into algebraic form by using finite difference scheme. A numerical technique has been developed to solve the above physical problem. Different shapes of fin have been studied by changing the length of the fin. Aluminium has been used as a fin material. Convective boundary conditions on the walls of the fin have been considered which represents the actual physical scenario. A mathematical formulation has been developed in the present study which can be used to study the effect of fin length and fin material for any real fin problem. Using the above formulation one can also study the 
temperature contour inside the fin for any fin length and fin material. MATLAB will be used to code the algebraic governing equation.

\section{REFERENCES}

[1] Date, Praful., \& Khond, V. W. (2013) Heat transfer enhancement in fin and tube heat exchanger, ARPN Journal of Engineering and Applied Sciences, vol. 8, No. 3, ISSN 1819-6608.

[2] Magarajan, U., Thundil karuppa Raj R., \& Elango T. (2012). Numerical study on heat transfer of internal combustion engine cooling by extended fins using CFD International Science Congress Association, vol. 1, no.6, 32-37.

[3] Matkar,M., \& Ravanan., P. M. (2011). Thermal Analysis of Copper Fin by FEA. International Conference on Operations and Quantitative Management. Nasik, India.

[4] Mishra, A.K., Nawal, S., \& Thundil, Karuppa Raj R. (2012), "Heat Transfer Augmentation of Air Cooled Internal Combustion Engine Using Fins through Numerical Techniques", Research Journal of Engineering Sciences, Vol. 1(2), 32-40, ISSN $2278-9472$.

[5] Nagarani, N., \& Mayilsamy, K. (2010). Experimental heat transfer analysis on annular circular and elliptical fins International Journal of Engineering Science and Technology, vol. 7, no.1,46-52.

[6] Patil, Nilesh K., \& Rathod, Manish K. (2012). Numerical investigation on effect of operating parameters on plate fin heat exchanger. Proceedings of the World Congress on Engineering, vol.3, 1-6.
[7] Paul, J. A.(2012). Experimental and parametric study of extended fins in the optimization of internal combustion engine cooling Using CFD. International Journal of Applied Research in Mechanical Engineering, vol 2, no.1, 81-90.

[8] Patil, Rajeev P., \& Dange, H.M. (2013). Experimental and computational fluid dynamics heat transfer analysis on elliptical fin by forced convection - International Journal of Engineering Research \& Technology, vol. 2, no.8, 1582-1594.

[9] Sandere, J. O., Wilsted, E. D., \& Mulaahy ,B. A. (1942). Cooling test of an air-cooled engine cylinder with copper fins on the barrel, NACA Report E-103

[10] Sharma ,Sanjay Kumar., \& Sharma, Vikas(2013) Maximizing the heat transfer through fins using CFD as a tool, International Journal of Recent advances in Mechanical Engineering (IJMECH) Vol.2, No.3, 13-28 